\title{
VÍCIOS, VIRTUDES E SENTIMENTO REGIONAL: SÃO PAULO, DA LENDA NEGRA À LENDA ÁUREA
}

Laura de Mello e Souza

Depto. de História - FFLCH/USP

\section{Resum 0}

Este artigo procura recuperar algumas das tradições que, ao longo dos tempos, viram os habitantes de São Paulo ora como bandidos, ora como heróis, buscando detectar matrizes que embasaram formulações historiográficas consagradas e hoje muito discutidas.

\section{Abstract}

The inhabitants of São Paulo have been considered through time as both bandits and heroes. This article revisits some of the main traditions upon which such constructs were built and tries to show how historians have dealt with them in the last century, as well as invented a tradition for the history of São Paulo.

\section{Palavias - Chave}

Paulistas - bandidos - heróis - tradição.

\section{Keywords}

Paulistas - bandits - heroes - tradition. 


\section{Os paulistas, entre a detração e a exaltação}

$\mathbf{U}$

ma certa historiografia paulista dos anos 20, 30 e 40 do século XX empenhou-se na construção de imagens positivas do passado da capitania de São Paulo, invocando sobretudo a "epopéia bandeirante" e os feitos que levaram ao recuo do Meridiano. Afonso Taunay e sobretudo Alfredo Ellis foram os principais expoentes dessa tendência. Até mesmo um grande historiador como Jaime Cortesão se deixou fascinar por essas abordagens, e o seu estudo sobre Antonio Raposo Tavares destaca o papel e o empenho dos sertanistas em ganharem terras para o rei de Portugal ${ }^{1}$. Hoje, historiadores como John Monteiro (1994) firmaram a idéia de que os paulistas regiam-se antes de tudo pelos interesses econômicos, dentro dos quais a força de trabalho indígena tinha o papel de destaque, não se preocupando primirdialmente em ganhar terras para el-rei.

Além de desbravadores, os paulistas foram invocados como potentados poderosos e ricos, e assim apareceram, por exemplo, na obra de Oliveira Vianna, para quem homens como Guilherme Pompeu eram Cresos capazes de dar recepções dignas de Versalhes. Já na época em que dominava a historiografia ufanista, contudo, houve em São Paulo quem dela divergisse, propondo análise instigante e original sobre o cotidiano dos sertanistas, marcado pela escassez e pela pobreza. José de Alcântara Machado é, nesse sentido, um marco, com Vida e Morte do Bandeirante (Souza 2000: 1191-1203).

Sertanista empenhado em defender os interesses da Coroa; patriarca milionário que encarna à perfeição o modelo do grande proprietário rural, senhor de domínios fechados sobre si mesmos ou homem rude, afeito à vida dura e simples dos matos e destituído de cabedais? Ou ainda homem rebelde, independente até do rei quando se tratasse de seus interesses particulares, e falto de qualquer escrúpulo moral ou religioso quando o assunto era o assalto de aldeamentos e a escravização de gentios? Paulista virou, indicam registros e historiadores, sinônimo de bandido: quando havia negócio tenebroso implicando extermínio de índio ou negro, contratava-se o serviço dos habitantes de Piratininga.

\footnotetext{
${ }^{1}$ Um balanço excelente da questão encontra-se em Ilana Blaj (1995).
} 
São tantas as imagens construídas sobre os paulistas ao longo dos séculos que o historiador se desconcerta. "Em relação aos paulistas, por vezes, as falas das autoridades metropolitanas na colônia se mostram ambíguas, pois alternam-se cartas onde os habitantes de São Paulo são longamente elogiados por sua bravura, fidelidade à Coroa e pelos serviços prestados, com outras onde são chamados de desobedientes, violentos e criminosos" (Blaj 1995: 271). Coevos célebres refletem essa perplexidade: se há Montoya (1639), Charlevoix (1757) e a Legenda Negra, há o ufanismo linhagista de Pedro Taques de Almeida Paes Leme (1772) ou de Frei Gaspar da Madre de Deus (1797): uns e outros, matrizes evidentes das leituras negativas ou positivas realizadas pela historiografia.

Por volta de 1690, o autor anônimo da Informação do Estado do Brasil e de suas necessidades louvava a capacidade dos paulistas de penetrarem o sertão e se sustentarem anos a fio de "caças do mato, bichos, cobras, lagartos, frutas bravas, raízes e vários paus". Se este autor ressalta os elementos positivos, há outros onde a familiaridade com o mato sugere aspectos negativos, aproximando os paulistas dos animas: "os paulistas se arrancharam por fora, buscando sempre a vizinhança do mato para se comunicarem com as feras, de quem herdavam os corações" (Abud 1985: 18 e 14). Útil em certas situações, destacando-se nesse sentido a familiaridade no trato com os matos, os traços de independência e autonomia não cessaram de incomodar as autoridades régias: "a vila de São Paulo há muitos anos que é República de per si, sem observância de lei nenhuma, assim divina, como humana", ponderou em 1692 o governador geral Antonio Luís Gonçalves da Camara Coutinho em carta enviada ao rei; ladrões dos sertões, impossíveis de castigar, eram igualmente refratários à obediência, observava-se na mesma ocasião: "Assim que me parece inutil persuadilos a que façam serviço a Vossa Majestade, porque são incapazes, e vassalos que Vossa Majestade tem rebeldes, assim em São Paulo, donde são moradores, como no sertão, donde vivem o mais do tempo; e nenhuma ordem do governo geral guardam, nem as leis de Vossa Majestade" (apud Blaj 1995: 272 e 273).

Qualidades e defeitos apareciam indissociados na qualificação dos paulistas durante todo o século XVII, e assim continuou depois. No "Fundamento Histórico" 
que introduz o poema Vila Rica, terminado em 1773, Cláudio Manuel da Costa resvala de passagem nessa contradição:

\begin{abstract}
"Os naturais da cidade de São Paulo, que tem merecido a um grande número de geógrafos antigos e modernos serem reputados por uns homens sem sujeição ao seu soberano, faltos de conhecimento e respeito que devem às suas leis, são os que nesta América tem dado ao mundo as maiores provas de obediência, fidelidade e zelo pelo seu rei, pela sua pátria e pelo seu reino" (Costa 1903: 152)
\end{abstract}

Vários autores registram, para os tempos remotos, a temeridade de um paulista insigne e certamente truculento que respondera às ameaças de uma autoridade que o procurava assustar com a chegada iminente do Tribunal do Santo Ofício dizendo que "receberia a Inquisição a frechas". Em 1640, os homens de São Paulo promoveram levantes populares contra os jesuítas, chegando a expulsá-los da capitania e assim lançando água no moinho de narrativas detratórias de matriz jesuítica, como as do já citado Montoya ou ainda as de outros religiosos como Francisco Jarque e Nicolau del Techo, ambas dos finais do século XVII (Boxer 1952).

Há quem acredite que a descoberta das minas deu às bandeiras paulistas a legitimidade que não tinham conseguido com o apresamento (Abud 1985: 32) Tendo sem dúvida determinado um ponto de inflexão, acredito contudo que o surgimento das minas tornou ainda mais complicado, no cenário americano, o já complexo papel dos paulistas. Vejamos por partes.

\title{
2. A importância da guerra emboaba
}

Poucos episódios ilustram tão bem os papéis paradoxais representados pelos paulistas quanto a Guerra dos Emboabas (1707-1709) ${ }^{2}$. As Minas tinham então pouco

\footnotetext{
${ }^{2}$ Sobre a guerra dos emboabas, há uma boa síntese em Charles R. Boxer, A Idade de Ouro do Brasil - dores de crescimento de uma sociedade colonial, p. 83-105. Entre os estudos mais específicos, ver José Soares de Melo, Emboabas, [1926], 1987; Eduardo Canabrava Barreiros, Episódios dos emboabas e sua geografia, 1984. Com alguns equívocos, Isaías Golgher, Guerra dos Emboabas, 1982.
} 
mais de 10 anos de existência, reunindo um aglomerado de arraiais ainda destituído de administração formal. Os primeiros descobridores eram quase todos paulistas, e conforme foram chegando forasteiros originários do litoral ou da Metrópole, começaram os conflitos em torno da posse das melhores terras minerais e do exercício do mando. Os paulistas chamaram esses adventícios de emboabas, e seguiram-se vários conflitos armados. D. Fernando Martins Mascarenhas de Lencastre deslocouse do Rio, que sediava seu governo, e tentou controlar a situação. Não conseguiu, e os emboabas aclamaram Manuel Nunes Viana, um dos seus, como governador das Minas. O caso é extraordinário: exceto no episódio lendário de Amador Bueno, que os documentos não confirmam, nunca antes os habitantes da América haviam ensaiado tomar o freio nos dentes, afrontando o poder metropolitano. Os emboabas, muitos deles reinóis, como se disse, o fizeram. Os paulistas protestaram fidelidade ao rei, apesar de fontes sugerirem que, quando da viagem "pacificadora" de Antonio de Albuquerque à região, tramaram em tupi, nas suas barbas, a morte do novo governante. Apesar desses ocorridos, os emboabas foram exaltados como fiéis, e os paulistas detratados como indômitos.

Uma das primeiras fontes sobre a guerra emboaba é o relato, parcialíssimo, de Rocha Pitta. Basta atentar para os adjetivos e concluir. Narra o historiador da América Portuguesa que as dissensões no arraial do Rio das Mortes tiveram início "por uma [dissensão] que fez um Paulista tirana e injustamente a um forasteiro humilde, que vivia de uma pobre agência. Desta sem-razão, alterados os outros forasteiros e desculpavelmente enfurecidos, solicitaram a vingança da vida de um e da ofensa de todos, e a conseguiram, se aquele homicida não se ausentara com tal aceleração que o não puderam alcançar, posto que por muitas partes o seguiram. Daquele delito e de outras crueldades dos Paulistas deram conta ao governador do Rio de Janeiro, que então era D. Fernando Martins Mascarenhas de Lencastro, pedindo-lhe um capitão que os regesse e mantivesse em paz... (Pitta 1980: 269). Mais adiante, ao narrar a adesão dos “forasteiros" a Manuel Nunes Viana, por eles aclamado como governador, Pitta justifica: "e juntando-se logo os povos dos três lugares, Sabarabuçu, Caeté e Rio das Velhas, caminharam a buscar a Manuel Nunes Viana, e o elegeram 
por seu governador e de todos os povos das Minas, para refrear os insultos dos paulistas e os obrigar a viverem sujeitos ao jugo das leis do reino, e não às de seu próprio arbítrio, pelas quais só se governavam, enquanto el-rei por seus governadores e ministros os não punha na obediência de vassalos, com a observância dos seus reais preceitos." Os povos das Minas de Ouro Preto e Rio das Mortes também acudiram a Nunes Viana, pedindo-lhe que aceitasse o cargo, ao que ele acedeu. $\mathrm{O}$ argumento era de que "o partido dos paulistas" estava "mui poderoso" naqueles distritos, "usando da liberdade e insolência em que costumavam viver, e conservando o ódio entranhável contra todos os forasteiros" (Id.: 271).

É digno de nota que Pitta invirta o argumento: quem desrespeita o governo português está, na realidade, garantindo o controle lusitano na América Portuguesa. A aparente insubordinação é, na essência, fidelidade ao Rei. Toda a narrativa sobre a chegada de D. Fernando Martins Mascarenhas de Lencastre às Minas é nitidamente empenhada, e deve ter feito escola entre relatos posteriores e entre a historiografia. Corria, diz-nos Pitta, que o governador era partidário dos paulistas e ia prender os forasteiros. Estes convenceram Manuel Nunes Viana, e foram esperar D. Fernando em Congonhas. Nunes Viana aparece quase constrangido no episódio, argumentando estar à frente do exército contra sua vontade. O chefe emboaba não teria se oposto ao avanço do governador, mas mesmo assim este preferira recuar, "deixando aqueles povos na sua rebelião, por não poder reduzi-los à obediência del-rei, posto que todos protestavam estar seguros nela, e que a alteração que fizeram, fora por sacudir o jugo tirânico em que os punham os paulistas, a quem D. Fernando protegia e descobertamente amparava: e que pretendiam pedir a el-rei lhes enviasse às Minas governador e ministros assistentes, que os governassem e mantivessem em paz" (Id.: 274).

Em seguida, quando narra a viagem pacificadora de Antonio de Albuquerque às Minas, qualifica os paulistas de "insolente turba", que o governador tentara em vão dissuadir de persistirem no "impulso, em que cometiam tão grande ofensa contra Deus e tanto delito contra el-rei” (Id.: 276). 


\title{
3. Críticas econômicas, religiosas, políticas e morais
}

Antes do episódio emboaba, as críticas e reticências com relação aos paulistas devem ser entendidas no contexto mais amplo daquilo que Sérgio Buarque de Holanda qualificou como "polêmica dos partidários da lavoura contra a exploração do subsolo" (1960, I/2: 308). Vieira foi um dos expoentes mais ilustres a se envolverem na disputa, imprecando contra o inchaço burocrático que decorreria da montagem da exploração aurífera:

\begin{abstract}
"Quantos administradores, quantos provedores, quantos tesoureiros, quantos almoxarifes, quantos escrivães, quantos contadores, quantos guardas no mar e na terra, e quantos outros oficiais de nomes e jurisdições novas, se haviam de criar, ou fundar com estas minas para vos confundir e sepultar nelas? [...] Não havia de ser vosso o escravo, nem vossa a vossa canoa, nem vosso o vosso carro e o vosso boi, senão para o manter e servir com ele. A roça haviam vo-la de tomar de aposentadoria para os oficiais das minas: o canavial havia de ficar em mato, porque os que cultivassem haviam de ir para as minas; e vós mesmos não havíeis de ser vosso, porque vos haviam de apenar para o que tivésseis préstimo: e só os vossos engenhos haviam de ter muito que moer, porque vós e vossos filhos havíeis de ser os moídos" (apud Ambires 2000: 134).
\end{abstract}

Vieira foi aliás um dos primeiros a designar de paulistas os habitantes de São Paulo, quando opinou sobre o problema da administração dos índios por particulares ${ }^{3}$. O jesuíta, já velho, presenciou o prestígio crescente que os homens de Piratininga foram alcançando no Nordeste como matadores de índio bravo ou de negro fugido, e que caminhou junto com a sua desqualificação. Escrevendo muito tempo depois, mas mostrando-se fiel a memórias coevas, Saint-Hilaire e o brigadeiro

\footnotetext{
${ }^{3}$ O termo "paulista" teria inclusive se perpetuado graças a Vieira e a seu voto ("Voto do padre Vieira sobre as dúvidas dos moradores de São Paulo acerca da administração dos índios") - é o que diz Juarez Donisete Ambires com base no Salvador de Sá de Charles Boxer. O trecho de Vieira: "até chegarem às terras de São Paulo, onde os moradores dela - que daqui por diante chamaremos Paulistas..." (apud Ambires 2000: 139).
} 
Machado de Oliveira registram bem esse momento de inflexão, situado possivelmente nos anos 70, quando, para combater os Gueréns, João Amaro chegou à Bahia comandando "um corpo de mamelucos já adestrados em tais empresas":

"Não eram os paulistas bem conhecidos no norte do Brasil, porque, habitantes da sua região meridional, era para este lado que lhes ficava mais a jeito o praticarem suas excursões no empenho de apreender índios e descobrir minas...[...]. Todavia, em todas as capitanias tinha se ouvido com admiração os nomes desses homens de ferro, sua coragem, e as afoutezas e animosidades com que afrontavam aos perigos e faziam guerra aos índios"" .

À medida que se tornavam conhecidos, os paulistas iam ganhando admiradores e opositores. Alguns, como Bartolomeu Lopes de Carvalho, perceberam que sua força era justamente a ambivalência de que se revestiam. Funcionário régio incumbido pela coroa de visitar as capitanias do sul e informar sobre a administração dos índios por particulares, Lopes de Carvalho tomou o partido dos apresadores ${ }^{5}$. No Manifesto que escreveu ao rei, defendeu a dureza no trato com os índios, afirmando "que se eles paulistas não foram com as suas entradas no sertão que já hoje estivéramos dos ditos gentios tragados e comidos...". E continuava:

\footnotetext{
${ }^{4}$ Oliveira (1897) deve ter se baseado nos escritos de viagem de Saint-Hilaire sobre São Paulo, muito próximos da passagem acima transcrita (Saint-Hilaire 1922: 62ss.).

${ }^{5}$ Um dos pontos altos da dissertação de Juarez Donisete Ambires, da qual me valho aqui, é o capítulo onde trata da oposição entre os partidários da administração dos índios por particulares, como Alexandre de Gusmão, Benci e Antonil, e aqueles que, como Vieira, a condenavam. À p. 130, diz o autor que o ouro, descoberto em 1693, foi determinante na simpatia da Corte para com a posição paulista, contrária à de Vieira: "As minas, contudo, em que a princípio Vieira não cria, tornaram-se uma realidade que estudiosos da questão apontam como a causa de peso para que as autoridades portuguesas, tanto religiosas quanto civis, pendessem para os paulistas e, é claro para os religiosos jesuítas contrários a Vieira. Perdedor na Bahia, torna-se também Vieira, na questão da administração dos índios por particulares, um perdedor na Corte". O extraordinário "Manifesto a Sua Majestade", de Lopes de Carvalho, encontra-se publicado em apêndice documental; é documento da Biblioteca da Ajuda, cód. 51-IX-33, fls. 370-3v. (Ambires 2000: 196-200).
} 
"e que eles paulistas eram os verdadeiros exploradores do Brasil, e nisto tinham feito grandes serviços a Vossa Majestade, pois com o seu temor, e armas afugentaram o mais do gentio bravo que avizinhava com os das marinhas, deixando lugares capazes para se povoarem, como também no sertão donde ficou mais franqueada a entrada àqueles que nesses lugares quiseram estender seus gados para sustento de todo o Brasil..." (apud Ambires 2000: 199-201).

Os paulistas garantiam, portanto, o avanço da colonização portuguesa na América. Isso não significava que fossem colonos perfeitos ou gente sem vício, dando-se mesmo o contrário: "estes moradores de São Paulo são gente indômita e incapaz de se reduzirem a termos especulativos ou práticos, porquanto entre eles, as suas leis são as da conveniência, e do gosto...” (Id.: 202).

Conforme ultrapassavam as fronteiras regionais, os paulistas iam, assim, adquirindo feição cada vez mais ambígua. Os qualificativos detratores também se espraiaram, galgando, nesse caso específico, as escarpas da Mantiqueira: vícios e defeitos paulistas passaram a ser também mineiros.

Nos anos que medeiam entre os primeiros descobertos - 1694 - e a guerra emboaba, encontram-se freqüentes alusões aos habitantes das Minas, sempre pouco elogiosas. Se os descobridores foram sobretudo paulistas, nem todos os mineiros eram originários de São Paulo, havendo-os das outras capitanias e, em número considerável, do Reino. Apesar disso, e durante o primeiro quartel do século XVIII, muitos dos defeitos atribuídos aos mineiros eram análogos aos até então atribuídos aos paulistas.

Em alguns casos, as críticas de cunho mais político ou moral migravam para o terreno religioso, numa época, aliás, em que a compartimentação entre tais instâncias podia ser inexistente. Veja-se, a propósito, uma carta escrita pelo Padre Belchior de Pontes a José Correia Penteado em 13/08/1718, "na qual declara o lastimoso estado em que então estavam as Minas":

"Se V.M. não toma este aviso, ao menos tome o que vê, que ao presente lhe servirá de exemplo, que são os senhores seus irmãos, que também cursaram ofadario dessas Minas enganosas, que só servem para as almas, que custaram o sangue de Cristo, rodarem pelo barranco do inferno: deste ao presente procuraram de se livrar os irmãos de V.M., e em todo caso serão livres, porque Cristo Senhor 
Nosso salva a todos os que buscam a paz e sossego de sua alma: esta paz ninguém a pode alcançar nas Minas; porque nelas o demônio em adjunto com o interesse reinam e cegam os olhos interiores das almas: e se há de cumprir a palavra de Deus: MUITOS SÃO OS CHAMADOS AO GRÊMIO DA IGREJA, E DELES POUCOS SE SALVAM. Deseje V.M. ser do número dos poucos, e isto com livrar-se com tempo dos males verdadeiros, que são os que V.M. vê, apalpa e quiçá também gosta: estes males não são trabalhos, tribulações, pobreza, injúrias, doenças e achaques; senão pecados, ambição, usuras, roubos, enganos, ladroices, homicídios, adultérios, soberba e inveja, que V.M. vê tudo isto e não sabe livrar-se deles para ganhar uma alma, que Deus lhe deu, e lhe custou seu precioso sangue, etc." (Fonseca s/d.: 247)

Mas a pouco e pouco, foi sobretudo no plano político que se firmaram as críticas aos paulistas e aos mineiros, sempre revestidas de roupagem ética. Sua insubordinação era fruto das lacunas da administração, e só desapareceria quando o mando se aperfeiçoasse. Ponderando sobre a necessidade de organizar a cobrança de impostos nas Minas, João Pereira do Vale escrevia a D.Pedro II em 7/12/1705:

"As minas ficam tão distantes desta cidade que não se pode formar juízo do seu estado, pois cada um fala nelas com o afeto que lhe ditam seus interesses, e ainda os que a elas vão, apenas concordam no que dizem, porque sendo tão dilatadas, nem todos penetram as asperezas daqueles montes, porque como homens que vão a negociar, aonde encontram a sua conveniência põem fim à jornada; porém, devesse supor que a abundância do ouro continua, porque sempre desta cidade está partindo gente para elas, e afirmam os de maior experiência e melhor ponderação que se do ouro que nelas se tira cada ano se pagassem os quintos e datas com pontualidade, teria V.Magde mais de cem arrobas cada ano.

"Esta arrecadação só será possível se o governo delas se estabelecer de modo que naqueles montes, desertos e caminhos possa resplandecer a justiça, sendo os patíbulos testemunhas de que os delinquentes são severamente castigados por V.Magde., assim como os inocentes favorecidos de sua real clemência, porque com a ligadura das leis e a administração da justiça nos desertos se fazem cidades, e estas, sem justiça, são seminários de facinorosos, quais se reputam os paulistas que, sem temor de Deus nem respeito às leis, vivem como feras e morrem como brutos, carregados de homicídios voluntários, roubos e insolências, porque nem contra eles há poder que os sujeite nem razão que os convença [ênfase acrescentado] e assim não pagam quintos, oprimem os pequenos, e por au- 
toridade própria se constituem tão livres que se pode duvidar se fora melhor não ser senhor daqueles tesouros em poder de tais vassalos" (Antonil 1968: 562-3).

Cultura e opulência do Brasil por suas drogas e minas, de Antonil, incorporou essa "mitologia" do vício paulista e mineiro. Verdadeira caixa de ressonância das autoridades administrativas do litoral, que temiam o colapso da economia açucareira ante a fuga de braços para a mineração, Antonil defendeu as plantações do litoral contra o que reputava a ilusão do ouro. Em 1700, Artur de Sá e Menezes, governador e capitão-general do Rio de Janeiro, havia lançado proibições sobre a venda para Minas de escravos subtraídos ao tabaco e ao açucar: quem desobedecesse teria os escravos confiscados e dois meses de prisão. Restringiu-se ainda a 200 o número de cativos que, desembarcando no Rio vindos da Costa da Mina, poderiam anualmente ser comprados pelos paulistas e seguir para as Minas. Este problema continuou preocupando o governador geral subsequente, D.Rodrigo da Costa, que de 1703 a 1705 não falou em outra coisa em sua correspondência com o rei e outras autoridades, escrevendo a D. Alvaro da Silveira em 1703 que as minas verdadeiras, capazes de enriquecer Portugal, eram e sempre foram a agricultura: mantêlas era condição de prosperidade para Portugal. No ano seguinte, em tom amargo, dizia que os "proveitos" advindos da permissão real de se explorarem minas na Bahia e em São Paulo resumiam-se na falta de escravos, tornados excessivamente caros, no abandono das culturas e, ainda por cima, no risco iminente de invasão estrangeira, seguindo-se a ruína total do estado do Brasil (Mansuy 1968: 33). As culturas vegetavam ou desapareciam. Um escravo nas Minas alcançava até 3 vezes o preço pago pelos plantadores do Nordeste: com eles, nenhum negociante queria comerciar.

Andreoni, vivendo na Bahia e privando da intimidade de governantes, certamente partilhava das mesmas opiniões. Deve ter obtido as informações que veicula em seu livro junto a altas autoridades da administração e do governo - por exemplo, os dados referentes à Casa da Moeda ${ }^{6}$. O conceito final de Antonil era tenebroso: o ouro que

\footnotetext{
${ }^{6}$ Defendo tal hipótese em "La conjoncture critique dans l'univers luso-brésilien au début du XVIII ${ }^{\text {ème }}$ siècle", artigo a ser publicado em coletânea organizada por Francisco Bethencourt para a Fundação Calouste Gulbenkian de Paris, sobre Portugal e o Atlântico.
} 
não se passava em pó ou moeda para os "reinos estranhos" acabava em cordões e brincos que enfeitavam, mais do que senhoras, as negras e mulatas mal-procedidas. Qualquer solução implicava no aperfeiçoamento da máquina governamental, e mais uma vez os qualificativos negativos eram morais: “... na administração da justiça se asseguram aos vassalos as vidas e as fazendas, ficando livres os caminhos que hoje se acham cheios de caveiras dos miseráveis a quem a ambição dos mais poderosos, por lhe roubarem o ouro, tirou a vida. O maior mal que se considera tem feito as minas é serem couto de foragidos, porque o soldado, o marinheiro, o negro e o delinquente, tanto que se colhem no caminho das minas estão seguros, e havendo lá justiça e poder, o soldado será reconduzido, o marinheiro tornará para o navio, o negro será restituído a seu senhor, e o delinquente castigado, e deste modo não haverá tantos fugitivos, porque o temor do castigo os fará abster da tentação" (Antonil 1968:565). Tão diverso de Vieira no tocante à administração dos índios por particulares, Antonil dele se aproximaria no que dizia respeito à desqualificação da empresa mineradora.

Em 1717, D. Pedro Miguel de Almeida Portugal, conde de Assumar, tomava posse do governo da capitania de São Paulo e Minas do Ouro, proferindo um notável discurso ante os camaristas que o recepcionavam. Exaltando primeiro a própria virtude e estirpe, o sacrifício a que se tinha sujeitado para servir o Rei, deixando para trás a família e se aventurando em terra longínqua e perigosa, Assumar passava em seguida a exaltar as qualidades necessárias aos vassalos: que os paulistas não se esquecessem delas, pagando a clemência real com bons préstimos.

Quando invoca a clemência real, Assumar aproxima mineiros e paulistas. Vejamos o trecho:

"veja-se o perdão geral, que el-rei D.Pedro, de gloriosa memória [...] concedeu na primeira abertura das Minas, perdoando todos os crimes até ali cometidos; mas nisto talvez se poderá entender que o interesse do mesmo rei obraria mais que a sua magnanimidade; mas da segunda anistia que diremos?" [e aqui, é ao episódio emboaba que se refere] "Depois daquele tempo, ó deplorável tempo! ó tempo de desgraças e de misérias! em que a boca de qualquer das vossas armas vomitava uma violência, uma atrocidade, um assassino, um homicida. Tudo isto não é nada: ateada a peste de uma civil guerra, em que com inumanos combates, quais lobos ferozes, 
ou quais outros tupinambás, tabajaras, tamoios, cataguazes, guaramãs, tremembés, paiaricús, janduís, carniceiros do gênero humano, uns com outros vassalos se devoravam. Depois de crueldades inauditas, que atroavam os ouvidos, e se ofendiam dos ecos, que o ar e o céu lhe comunicava (sic) com o clamor do filho pela morte do pai; com os do amigo pela falta do companheiro; enternecidos os corações com os gemidos das viúvas e com o desamparo das donzelas, depois de tudo isto enfim veio o perdão geral: não é isto ser pai mais e mais que piedoso? pois vendo que nem o mesmo rigor e aspereza do suplício seria capaz de expiar a atroz enormidade de tantos crimes, achou aquele compassivo rei que a indulgência no harmônico governo desta República se não respire mais que paz, tranqüilidade e sossego; mas eu espero que, capacitados de razões tão convincentes, se levantem desde hoje aqueles intrépidos ânimos, ainda agora abatidos, e sepultados nas desgraças, frutos infaustos da ambição, da soberba e da altiveza, e que a glória antiga dos descobrimentos com mais força se renove, e deva el-rei nosso senhor aos de São Paulo adquirirem-lhe maiores tesouros, para que enriquecidos e opulentos os seus vassalos neste continente, possam com menos avareza e mais generosidade aumentar-se os seus erários com mais quintos tão devidos pelas humanas leis, quanto pelas divinas..."

Irmanados na rebeldia, os vassalos de São Paulo e de Minas tinham um crédito com o rei pelos serviços prestados no passado. Os tempos, contudo, começavam a ser outros: não mais de tropelias, caça a índio, descobertos auríferos, e sim de consolidação do mando, pagamento de impostos, defesa do território. A lenda negra, contudo, já havia deitado raízes no imaginário luso-brasileiro .

\footnotetext{
${ }^{7}$ Publiquei pela primeira vez esse documento em "Um documento inédito: o discurso de posse de D. Pedro de Almeida, Conde de Assumar, como governador das capitanias de São Paulo e Minas do Ouro em 1717", in Norma e Conflito - aspectos da História de Minas no século XVIII, Belo Horizonte, Editora UFMG, p. 30-42. Há duas versões conhecidas do documento, uma na Biblioteca da Ajuda, Seção de Manuscritos, 54/XIII/16, outra no Arquivo Distrital de Évora, CXVI/2-13, n. 27.

${ }^{8}$ Para Raquel Glezer, "a lenda negra que apresenta os habitantes de São Paulo como cruéis assassinos, inimigos dos índios e dos padres... foi elaborada nos séculos XVI e XVII" pelos padres jesuítas. Diversamente, no século XVIII foi elaborada uma "lenda dourada" pelos linhagistas e descendentes dos conquistadores que eram Pedro Taques e Frei Gaspar. Nessa lenda, os bandeirantes foram considerados "concretizadores da obra da colonização, integradores da população indígena no povo brasileiro". Ver Chão de terra - um estudo sobre São Paulo colonial, São Paulo, tese apresentada ao concurso de livre-docência em Metodologia da História, USP, 1992, p. 47 [ex. mimeografado]. Ver ainda Milena Maranho, A opulência relativizada - significados econômicos e sociais dos níveis de vida dos habitantes da região do planalto de Piratininga - 1648-1682, Dissertação de Mestrado sob orientação de Leila Mezan Algranti, Departamento de História, IFCH, UNICAMP, setembro 2000.
} 


\section{A resposta dos linhagistas}

Na segunda metade do século XVIII, três indivíduos aparentados, dois deles paulistas e um mineiro de origem paulista, produzem obras que expressam o sentimento de orgulho que os habitantes de São Paulo sentiam das suas origens. São eles Pedro Taques de Almeida Paes, frei Gaspar da Madre de Deus e Cláudio Manuel da Costa. As obras, a Nobiliarquia Paulistana, a Memória Histórica da Capitania de São Paulo e o poema Vila Rica, antecedido de um Fundamento Histórico (Souza 1967: 161-191).

ParaAlfredo Bosi, homens como Pedro Taques e Frei Gaspar representariam a "retórica dos intelectuais porta-vozes do sistema agromercantil", louvaminheira e recorrente nas nossas letras desde sempre. A "retórica humanista-cristã" dos jesuítas aproximaria cultura e culto, utopia e tradição. A daqueles homens, "amarra firmemente a escrita à eficiência da máquina econômica, articulando cultura e colo" (Bosi 1992: 36-7).

Apesar de engenhosa, essa hipótese carece de embasamento histórico, e peca por homogeneizar posições que se tornavam, naquela época, cada vez mais dependentes de conjunções regionais. Com a descoberta das Minas, como se viu neste artigo, os antigos e enraizados interesses agromercantis do Nordeste clamaram contra o perigo ao sul, para tanto lançando mão até de argumentos ideológicos. Eram substancialmente distintos o contexto no qual, em Pernambuco, Loreto Couto e outros construíram imagens edificantes sobre os heróis da restauração e o contexto em que, no sul, os paulistas se empenharam em dourar as andanças sertanistas. Se Pernambuco era região desde cedo nevrálgica na economia e na política do império da América Portuguesa, dotada de aristocracia consolidada e, quando não totalmente branca, empenhada no embranquecimento, São Paulo se mantivera, mais do que excêntrica, fechada sobre si mesma e sobre a sua mestiçagem, falando, até o século XIX, a língua geral do sul. Após anos duros, em que a capitania chegara inclusive a perder a autonomia, os habitantes de São Paulo recriavam o passado, idealizando-o e configurando ideologicamente o "paulistanismo". Taques e Frei Gaspar pertenciam às elites bandeirantes - Ilana Blaj lembra que, "em São Paulo de fins do XVII e inícios do XVIII, [...] a maioria dos paulistas proeminentes era parente de Pedro Taques de Almeida" (Blaj 1995: 297-8) 
-; seus escritos enaltecem os feitos dos ancestrais, deixando de lado os aspectos negativos que sempre haviam acompanhado a exaltação dos paulistas e realizando o primeiro grande esforço para separar virtudes de vícios. Até a mestiçagem, antes com freqüência invocada como "defeito", foi valorizada por Frei Gaspar e considerada como elemento enobrecedor (Abud 1985: 93). A literatura linhagística dos paulistas era também uma resposta à má fama dos sertanistas, e uma tentativa de mostrar virtudes onde quase só se viam vícios. Se os pernambucanos eram vassalos reconhecidos como especiais - já no século XVII tiveram diocese, bispo, cidade, e, ao explusar os holandeses, deram provas inequívocas de fidelidade ao rei-, os paulistas eram, quase sempre, uma pedra no sapato, e a arte de bem governar consistia muitas vezes em fazer com que o Estado metropolitano conseguisse tirar proveito desses homens difíceis.

Em Minas, por fim, o sentido da exaltação foi distinto, pois a região mal se aproximava de um século de existência: a Cláudio Manuel da Costa coube inventar uma tradição, atrelando a capitania recente e mal sedimentada à história mais antiga de São Paulo. Os feitos bandeirantes e a antigüidade do povoamento paulista serviam assim de antídoto ao rápido e tempestuoso processo de ocupação do solo mineiro. Qualificar positivamente os paulistas significava soterrar os qualificativos detratores que, desde cedo, haviam incidido sobre os mineiros, como se viu, por exemplo, na carta do padre Belchior de Pontes.

Lançavam-se as bases do orgulho paulista, que inspirou a historiografia a que se aludiu no início destas reflexões. O regionalismo ufanista foi a resposta ideológica à generalização das detrações ou, quando muito, às ambigüidades. Como boa ideologia, desbastou as contradições inerentes ao papel histórico dos paulistas e sublinhou, isolandoas, as virtudes que, até então, nunca haviam se mostrado em separado dos vícios. 


\section{Referências Bibliográficas}

ABUD, Katia Maria. O sangue intimorato e as nobilíssimas tradições - a construção de um símbolo paulista: o bandeirante. Tese de Doutoramento, FFLCH/USP, 1985.

AMBIRES, Juares Donizete. Os jesuitas e a administração dos índios por particulares em São Paulo, no último quartel do século XVII. Dissertação de Mestrado, FFLCH/USP, 2000.

BLAJ, Ilana. A trama das tensões - o processo de mercantilização de São Paulo colonial (1681-1721). Tese de Doutoramento, FFLCH/USP, 1995.

BOSI, Alfredo. Dialética da colonização. São Paulo, Companhia das Letras, 1992.

BOXER, Charles R. Salvador de Sá and the struggle for Brazil and Angola. Londres, Athlone Press, 1952.

COSTA, Cláudio Manuel da. Obras completas. Rio de Janeiro, Garnier, 1903.

FONSECA, Manuel da. Vida do venerável padre Belchior de Pontes. São Paulo, Melhoramentos, s/d.

HOLANDA, Sérgio Buarque de. História Geral da Civilização Brasileira (I/2). São Paulo, Difusão Européia do Livro, 1960.

MANSUY, Andrée (org.). Cultura e opulência do Brasil por suas drogas e minas de André João Antonil. Paris, Institut des Hautes Études de L’Amérique Latine, 1968.

OLIVEIRA, Brigadeiro José Joaquim Machado de. Quadro histórico da Província de São Paulo até o ano de 1822. $2^{\mathrm{a}}$ ed. São Paulo, Typografia Brasil de Carlos Gerke e Companhia, 1897.

PITTA, Sebastião da Rocha. História da América Portuguesa desde o ano de mil e quinhentos do seu descobrimento até o de mil e setecentos e vinte e quatro. $2^{\mathrm{a}}$ ed. Lisboa, Francisco Arthur da Silva, 1880.

SOUZA, Antonio Candido de Melo e. Literatura e sociedade. São Paulo, Companhia Editora Nacional, 1967.

SOUZA, Laura de Melo e. "Vida e morte do bandeirante" in Intérpretes do Brasil (org. Silviano Santiago). Rio de Janeiro, Nova Aguilar, 2000. 